Open Access

\title{
Application effect of extensively hydrolyzed milk protein formula and follow-up in preterm children with a gestational age of less than 34 weeks: study protocol for a randomized controlled trial
}

\author{
Li-Ping Yin ${ }^{\dagger}$, Li-Juan Qian ${ }^{\dagger}$, Huan Zhu, Yan Chen, Han Li, Ji-Nan Han and Li-Xing Qiao*
}

\begin{abstract}
Background: The average incidence of preterm birth in the world is up to $11.1 \%$, and deaths of preterm children account for more than $50 \%$ of neonatal deaths. Gastrointestinal function of preterm children with a gestational age less than 34 weeks is immaturely developed. For preterm children who can only be fed with formula due to their mothers' sickness, choosing a suitable formula can not only meet the high nutritional needs of preterm children, but also solve their low gastrointestinal tolerability, and is thus very important.

Methods/Design: The study is a prospective, randomized, single-blind and controlled clinical trial. Preterm children with a gestational age less than 34 weeks meeting the inclusion criteria who cannot be breastfed will be included. To demonstrate the application effect of extensively hydrolyzed milk protein formula on the target population, preterm children will be randomized into two groups, 185 subjects in each group. The observation group will be fed with extensively hydrolyzed milk protein (100\% whey protein) formula, while the control group will be fed with preterm children's formula until the children are discharged from the neonatal intensive care unit (NICU). All the formula involved in this study will be from Dumex. After discharge, both groups will be uniformly fed with formula for 0 to 6-month-old infants. For statistical analysis, a chi-square test and Student's $t$ test will be applied using SAS 9.4.

Discussion: This will be the first randomized controlled clinical study with long-term observation of the growth and development of preterm children during the NICU stay and at 3-month follow-up after discharge from the NICU. Results from this study will be used to determine whether the extensively hydrolyzed formula is more suitable for the low gastrointestinal tolerability of preterm children, and also whether feeding preterm children who are fed with such formula during the NICU stay with ordinary infant formula after discharge from the NICU would affect the normal growth and development of preterm children in the early stage of their lives.
\end{abstract}

Trial registration: This study was registered with the Chinese Clinical Trial Registry (http://www.chictr.org.cn/) with number ChiCTR-IOR-14005696, on December 22, 2014.

Keywords: Extensively hydrolyzed formula, Preterm children, Feeding intolerance, Growth and development, Follow-up

\footnotetext{
* Correspondence: qiao_lixing@163.com

${ }^{+}$Equal contributors

Department of Paediatrics, Zhongda Hospital Southeast University,

87 Dingjiaqiao, Nanjing 210009, China
} 


\section{Background}

The neonatal period is a special period of life, in which the infant gradually transforms from complete dependence on the mother for survival into a mature individual. In 1976, the World Health Organization (WHO) defined preterm children as newborns with a gestational age of $<37$ weeks ( $<259$ days) [1]. In 2005, the American Academy of Pediatrics and the American College of Obstetricians and Gynecologists [2] defined newborns with a gestational age of $34-36^{+6}$ weeks as late preterm birth, and less than 34 weeks as early preterm birth; in 2012, the WHO [3] defined preterm children with a gestational age of $<28$ weeks as extremely preterm birth, $28-31^{+6}$ weeks as very preterm birth, $32-36^{+6}$ weeks as moderate preterm birth, and $34-36^{+6}$ weeks as late preterm birth. The incidence of preterm birth varies greatly in different countries. In 2010, the incidence of preterm birth in 11 countries worldwide was $\geq 15 \%$ [4]. The average incidence of preterm birth all over the world is up to $11.1 \%$. A total of 14.9 million preterm children are born worldwide every year [5], and in these preterm live births, more than 1 million preterm children eventually die [6], accounting for more than $50 \%$ of neonatal deaths. In China, there is little data on the incidence of preterm birth nationwide. The WHO reported that the incidence of preterm birth in China in 2010 was $<10 \%$ [4]. The number of preterm children in ten countries including China accounts for $60 \%$ of the world's total. The mortality of preterm children in China is very high. From 2000 to 2008, preterm children led to $14-15 \%$ of deaths of children younger than 5 years old in China [7]. The younger the gestational age, the lower the birth weight is and the higher the mortality is. According to the above data, we find that in all medical problems of newborns, the improvement of the survival rate and quality of life of preterm children is the target that the world focuses on tackling.

The fetus in utero obtains nutrition through the placenta as a parenteral nutrition (PN) pathway. After birth, the newborns need to switch to enteral nutrition, while the completion of enteral nutrition requires effective and coordinated sucking-swallowing, gastric emptying, intestinal peristalsis and the digestion and absorption of nutrients. However, these functions of preterm children are immature, and the younger the gestational age, the more immature these functions. First, the increase in the extensibility and absorption area (microvilli) of the gastrointestinal tract of preterm children is mainly completed in the last 3 months of pregnancy [8]. Second, the suckingswallowing-breathing action of preterm children with a gestational age of less than 32 weeks is much more uncoordinated; only children with a gestational age of 34-35 weeks have coordinated nutritive sucking [9]. In addition, the gastrointestinal motility of preterm children is weak, and the duodenum of preterm children with a gestational age of $<32$ weeks lacks the spread of migrating motor complex (MMC) [10]. Until after the gestational age of 34 weeks, clear and ever-increasing MMC gradually emerge. The above mechanisms lead to prolonged gastric emptying time and intestinal transit time of food in preterm children, and thus preterm children with a gestational age of less than 34 weeks are prone to gastroesophageal reflux, feeding intolerance (FI), delayed meconium drainage, intestinal dilatation and other phenomena. In addition, the development of digestive enzymes in preterm children is also very immature, and preterm children have inadequate secretion and low activity of gastric acid, gastric protease-pepsin and pancreatic protease, which weaken the ability of the gastrointestinal tract to hydrolyze protein into peptides and amino acids [10]; the concentration of pancreatic lipases and duodenal bile acids is very low [11], which reduces the intestinal absorption of lipids, especially the long-chain fatty acids (LCT). Therefore, preterm children are also prone to extrauterine growth retardation (EUGR) caused by inadequate absorption of enteral nutrition. Currently, a large number of studies have shown that extrauterine growth retardation has definite influences on the subsequent cognition and mental development of preterm children [12].

Nutritional support in the neonatal period is one of the basic conditions for survival of preterm children. Preterm children born in advance for various reasons need parenteml nutrition if enteral nutrition cannot meet their needs for growth and development. Although parenteral nutrition supplement can meet the temporary nutritional needs of preterm children, long-term parenteral nutrition has brought a series of problems, such as difficulties in peripheral venous puncture, susceptibility to complication by infections after central venous catheterization, parenteral nutrition-associated cholestasis (PNAC) and other complications. The ultimate goal of nutritional support in preterm children is to not only reach the normal growth speed of normal fetuses of similar gestational age in utero, but also have similar composition and function to normal fetuses. The ideal growth rate of preterm/low-birth-weight children during the neonatal intensive care unit (NICU) stay, by referring to the growth rate of normal fetuses in utero [13], is required as follows: average daily weight gain of $15 \mathrm{~g} / \mathrm{kg}$, weekly body length growth of $1 \mathrm{~cm}$ and weekly head circumference growth of $0.5-1 \mathrm{~cm}$. However, preterm children after birth are faced with respiratory, digestive and other problems. For preterm children with various immaturely developed systems, how to solve the conflict between the high nutritional demands and low gastrointestinal tolerability of preterm children is a very realistic and important issue. Therefore, we need an appropriate early enteral nutrition management strategy for preterm children, although there is 
already a lot of consensus [14, 15], such as breastfeeding, initiation of microfeeding as early as possible, achieving full enteral nutrition as soon as possible, and shortening the time of parenteral nutrition in order to reduce complications. It is preferred to feed preterm children with their mothers' breast milk [14], because such feeding can reduce the incidence of feeding intolerance, neonatal necrotizing enterocolitis (NEC), nosocomial infections, and growth and developmental retardation in preterm children [16]. In the event of inadequate supply of breast milk due to various reasons or inability of breastfeeding due to maternal diseases, breast milk provided by qualified breast milk donors becomes the second-best nutritional source for preterm children [17] During October 2010 to December 212, a multicenter double-blind controlled study conducted in Canada [18] found that the breast milk of donors was equally safe and effective as the breast milk of preterm children's mothers, and after longterm follow-up and study, found that donor breastfeeding was favorable for the development of the nervous system in preterm children. In Taiwan, China [19], the breast milk in the breast milk bank is mainly used for feeding preterm children, infants with feeding intolerance and other infants suffering from metabolic disorders. Currently, many developed countries have established large breast milk banks, and breast milk can be shared even via the Internet [20]. However, the breast milk in breast milk banks is mostly for full-term children, whose nutritional ingredients cannot meet the needs of growth and development of preterm children. Breast milk banks have not been set up in most areas of China, and no unified standard donor screening, breast milk collection, disinfection, preservation and feeding practices have been established. The rural population accounts for the majority in China. Rural areas and small cities lack the capacity to treat preterm children, so preterm children are often sent to NICU in large cities for hospitalization. Their homes are often far away from the hospital, and China's NICUs are mostly accompanyfree wards, so family members cannot participate in feeding and care. Besides, many mothers cannot breastfeed because of their illness, and thus, preterm children hospitalized in NICUs in China are mostly fed with formula.

In China, preterm children with a gestational age of less than 34 weeks are mostly fed with preterm children's formula, and such milk powder provides sufficient energy, protein, vitamins and minerals and features a high growth rate in preterm children. However, excessive weight gain in early infancy will increase the risk of metabolic diseases and cardiovascular diseases in adulthood $[21,22]$. The probabilities of feeding intolerance and neonatal necrotizing enterocolitis and overall mortality in preterm children fed with preterm children's formula are significantly higher than in children fed with breast milk or donated breast milk [23-25]. Therefore, choosing a milk powder more suitable for the intestinal function of preterm children with a gestational age of less than 34 weeks is very important.

Hydrolyzed formula is to hydrolyze protein in milk powder to polypeptides, peptides and free amino acids with bio-lyase, heating, ultrafiltration and other special technologies. The American Academy of Pediatrics (AAP) refers to formula whose peptide molecular weight is less than $3000 \mathrm{Da}$ as extensively hydrolyzed formula (EHF) [26]. According to the protein ingredient therein, the formula can be divided into hydrolyzed protein formula, hydrolyzed soy protein formula and hydrolyzed rice protein formula; according to the milk protein ingredient therein, the formula can be divided into hydrolyzed whey protein, hydrolyzed casein, and hydrolyzed whey protein/casein. The low-molecular-weight peptides and small amounts of free amino acids in extensively hydrolyzed milk protein formula have greatly reduced the conformation and sequence of allergen idiotope, and thus the antigenicity is greatly lowered. The milk powder is mainly used for the treatment of cow's milk protein allergy (CMPA) [27]. Researchers have fed preterm children in their early stage of life with EHF to prevent the occurrence of CMPA $[28,29]$, but there is no conclusion on whether it is effective.

EHF has cracked milk protein to low-molecularweight peptides and partial amino acids, favorable for the gastrointestinal tolerability of preterm children. Frati et al. [30] and Staelens et al. [31] found by adopting different methods that the gastric emptying of EHF was significantly faster than the ordinary formula group; Mihatsch et al. [32] used carmine as a fecal marker and found that in preterm children, the gastrointestinal transit time of extensively hydrolyzed formula was 9.8 hours, while that of standard ordinary formula was 19 hours. The main mechanisms that EHF is favorable for the gastrointestinal tolerability of preterm children are summarized as follows: (1) it promotes gastric emptying [30, 31, 33, 34]; (2) it accelerates gastrointestinal transit [32]; (3) it reduces the activity of opioid receptor agonist-milk protein [35]; and (4) it induces motilin (MOT) and gastrin (GAS) secretion [36], thereby reducing the incidence of gastroesophageal reflux (GER) [30, 34, 37], feeding intolerance, etc., in preterm children [38] so as to achieve full enteral nutrition as soon as possible and reduce the time of parenteral intravenous nutrition and a series of complications caused by parenteral nutrition.

Each $100 \mathrm{ml}$ of the EHF used in this study can provide $66 \mathrm{kcal}$, whose protein-to-energy ratio $(\mathrm{P} / \mathrm{E})$ is $2.42 \mathrm{~g} /$ $100 \mathrm{kcal}$, lower than the $\mathrm{P} / \mathrm{E}$ recommended by the European Society for Paediatric Gastroenterology, Hepatology, and Nutrition (ESPGHAN) [39]. Can extensively hydrolyzed milk protein formula meet the high 
nutritional needs of preterm children? Current study findings have differing conclusions [40-44]. Some studies conclude, by detecting the concentrations of amino acids in serum and urine and intestinal absorption of nitrogen after preterm children are fed with different milk powders, that the protein content in hydrolyzed milk protein formula should be higher than ordinary preterm children's formula in order to meet the needs of preterm children for growth and development [40-42]. However, these studies all have too small sample size (15 cases, 21 cases, 16 cases), the period of literature [40] study is too short (the conclusion is drawn from determination of plasma amino acid concentrations only after cross feeding with the two kinds of milk powder for 5 days), and in the above studies, the preterm children began to be fed with hydrolyzed formula after achieving full enteral feeding (EF) or 1 week after birth instead of feeding with hydrolyzed formula immediately after birth. Szajewska et al. [43] conducted a randomized controlled study of up to 12 weeks. The authors randomized lowbirth-weight children for feeding with different milk powders, then tracked and monitored the growth and development (weight, body length and head circumference growths) and all plasma parameter indicators (urea, albumin (ALB), prealbumin, transferrin, and concentration of each amino acid) of these infants at the beginning of feeding, 4 weeks, 8 weeks and 12 weeks after feeding, and found that the nutrition of extensively hydrolyzed whey protein formula was equivalent to that of the standard preterm children's formula. In China [44], a multicenter (eight domestic first-class grade 3 hospitals) controlled clinical study from February 2012 to December 2013 found that extensively hydrolyzed milk protein formula could promote the gastrointestinal motility of preterm children and accelerate their metabolism and excretion of bilirubin, without increasing the occurrence of EUGR at discharge. Besides, there is no study at home and abroad on whether feeding preterm children with relatively low-energy low-protein extensively hydrolyzed milk protein formula in the early stage of life will affect their subsequent growth and development. Although studies $[28,29]$ respectively followed up preterm children and extremely low-birth-weight children after feeding with EHF for the early stage of life for 12 months and 5-7 years, these two studies were conducted only to observe whether EHF could prevent the subsequent occurrence of CMPA in preterm children, without tracking and observing the growth and development of those preterm children.

The protein in the extensively hydrolyzed milk protein formula used in this study is $1 \%$ whey protein, without containing casein. A study has found that the higher the casein content, the slower the gastric emptying [45]. Each $10 \mathrm{ml}$ of the EHF we use provides $66 \mathrm{kcal}$ with osmolality of $250 \mathrm{mOsmol} / \mathrm{L}$, lower than traditional preterm children's formula. Another study has also found that the higher the calories provided by each $100 \mathrm{ml}$ of formula, the slower the gastric emptying [46]. Therefore, in this study, the gastric emptying time and gastrointestinal transit time in preterm children fed with extensively hydrolyzed milk protein formula will be accelerated, thereby reducing the incidence of feeding intolerance in the preterm children, achieving full enteral feeding as soon as possible, shortening the time of parenteral nutrition, and reducing the occurrence of complications associated with parenteral nutrition. This formula has cracked milk protein to low-molecular-weight peptides and partial amino acids, it reduces the intestinal load of protein digestion in preterm children, and is thus favorable for the gastrointestinal capacity of preterm children for protein digestion and absorption. Moreover, medium-chain triglycerides fat (MCT) in the formula accounts for $40 \%$ of total fat, which is favorable for preterm children's fat absorption and utilization. The energy and protein provided by each $100 \mathrm{ml}$ of the milk powder are lower than traditional preterm children's formula, but it may not affect the early nutrition of preterm children due to the abovementioned features. Can feeding preterm children with a gestational age of less than 34 weeks during the NICU stay with extensively hydrolyzed milk protein formula meet the preterm children's needs for early normal growth and development during hospital stay and after discharge? In addition to observation of the preterm children's growth and development during the NICU stay, our study will also track and follow up these preterm children for at least 3 months after they are discharged from the NICU.

\section{Methods/Design}

A prospective, randomized, single-center, single-blind and controlled clinical trial will be conducted in preterm children with a gestational age of less than 34 weeks meeting the inclusion criteria who cannot be breastfed. The implementer of the study will be the NICU of Zhongda Hospital Southeast University. The majority of the center's preterm children are transferred from other hospitals in Nanjing or nearby towns, wherein most preterm children who cannot be breastfed because their mothers suffer from infectious diseases or other severe diseases requiring long-term medication are also transferred to our hospital. Most preterm children hospitalized in our hospital's NICU can only be fed with formula. Every year, about 2,000 newborns are hospitalized in our hospital's NICU, and preterm children with a gestational age of less than 34 weeks account for 10 $15 \%$ of the inpatients, of whom about two thirds can only be fed with formula. 


\section{Objectives}

Primary objective

To determine whether feeding preterm children with a gestational age of less than 34 weeks during the NICU stay with extensively hydrolyzed milk protein formula can reduce the rate of food intolerance or not.

\section{Secondary objective}

To test if the feeding preterm children with a gestational age of less than 34 weeks during the NICU stay with extensively hydrolyzed milk protein formula can accelerate the time to achieve full enteral feeding, shorten the time of parenteral nutrition and NICU stay, benefit spontaneous fecal discharge, reduce the occurrence of other complications associated with parenteral nutrition, and meet the nutritional needs of preterm children during the NICU stay, without affecting the early growth and development of these preterm children during hospitalization and after discharge.

\section{Study population}

\section{Recruitment of participants}

Preterm children hospitalized in the NICU of Zhongda Hospital Southeast University in line with the inclusion criteria are recruited as participants (Fig. 1).

Inclusion criteria:
1. Gestational age $<34$ weeks

2. Children who can only be fed with formula due to their mothers' sickness

3. Children who are transferred to our hospital's NICU immediately after birth, and have not started any enteral feeding before and during transfer, including water, glucose, formula, drugs, etc.

4. Children whose cardiovascular, blood and nervous systems are stable when transferred to the NICU

Exclusion criteria:

1. Occurrence of vomiting, abdominal distension, gastrointestinal hemorrhage or necrotizing enterocolitis (NEC) before preparation for enteral feeding

2. Occurrence of cardiovascular, blood and nervous system instability (such as shock, disseminated intravascular coagulation (DIS), frequent convulsions, coma) before preparation for enteral feeding

3. Discovery of gastrointestinal malformations (esophageal atresia, esophageal fistula, biliary atresia, Hirschsprung's disease, anal atresia, omphalocele, gastroschisis, congenital malrotation, etc.) before preparation for enteral feeding or after feeding

4. Children with congenital metabolic diseases and chromosomal disorders

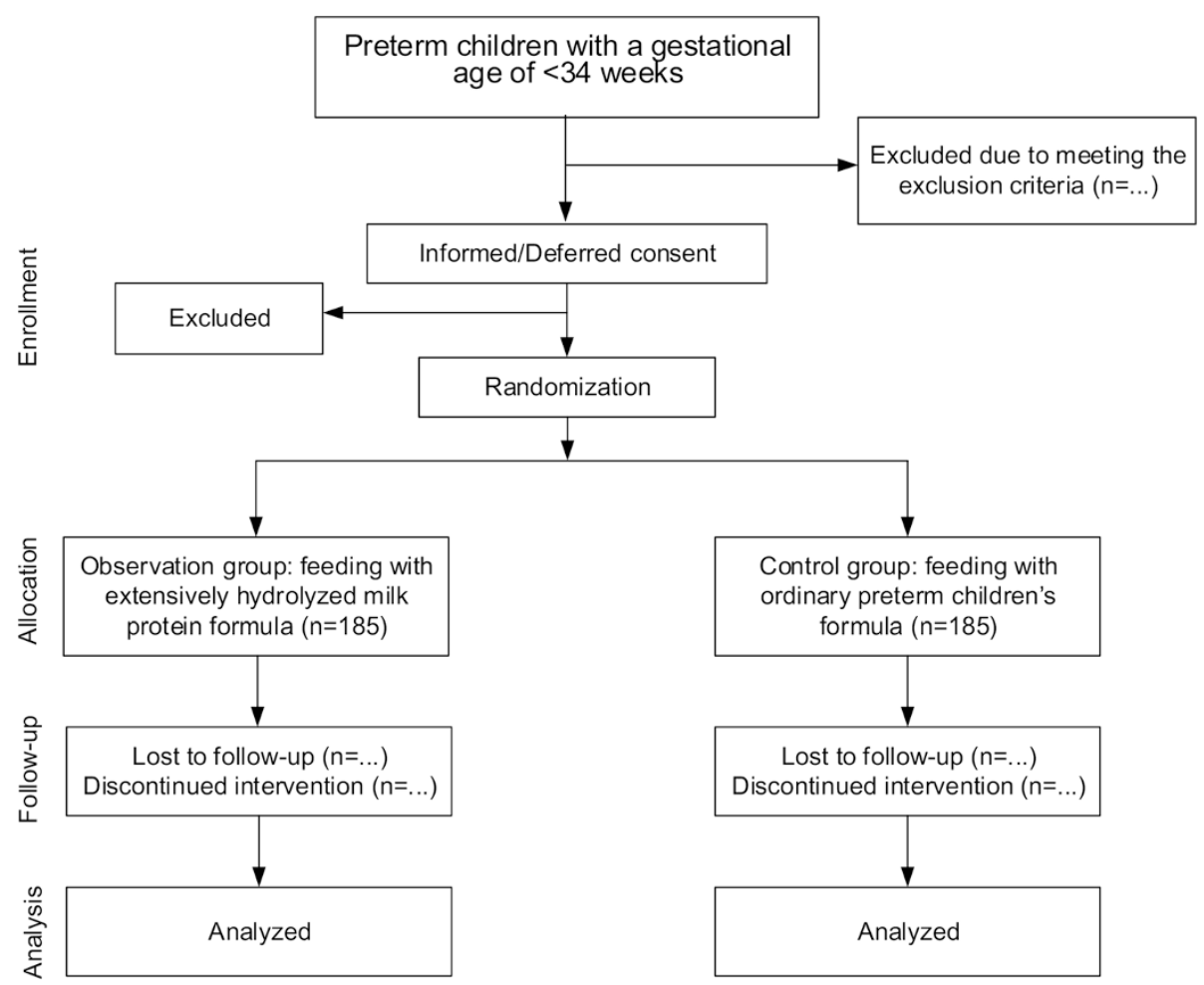

Fig. 1 CONSORT flowchart of subject enrollment 
5. Children with other serious congenital disorders (diaphragmatic hernia, cyanotic congenital heart disease, moderate to severe Pierre-Robin syndrome, etc.)

6. Renal failure due to various causes

7. Children whose head computed tomography (CT) or B-mode head ultrasound prompts serious intracranial hemorrhage or hydrocephalus

8. Use of drugs affecting gastric motility and gastric acid secretion $\left(\mathrm{H}_{2}\right.$ receptor antagonists, proton pump inhibitors, gastrointestinal drugs)

9. Occurrence of stage III necrotizing enterocolitis during hospital stay requiring transfer to a Children's Hospital for observation and surgical treatment

10. Replacement for formula during hospital stay

11. Death during hospital stay

12. Early discharge against the criteria for discharge from the NICU

13. Children who suffer from diseases requiring parenteral nutrition or serious illness requiring intensive care unit (ICU) hospitalization or requiring hospitalization and surgery

Criteria for discharge from the NICU or transfer to direct rooming-in (DRI):

1. Corrected gestational age $\geq 34$ weeks, and weight $\geq 1500 \mathrm{~g}$

2. No need for oxygen inhalation, stable vital signs, no apnea phenomenon

3. Able to suck formula on their own, and coordinated sucking-swallowing-breathing action

4. Having achieved full enteral feeding, daily milk volume $\geq 150 \mathrm{ml} / \mathrm{kg}$, no need for any intravenous medication

5. Able to maintain normal body temperature at room temperature of $22-24{ }^{\circ} \mathrm{C}$

6. Each system is free from life-threatening pathological conditions

7. Birth weight has been restored, and weight begins to grow steadily

\section{Randomization and blinding}

Randomization will be conducted by a researcher not involved in the recruitment and treatment of the participants. Concealed allocation will be performed using a set of random numbers placed in sealed opaque envelopes. The participants who meet the eligibility criteria will be divided into two groups by the physicians on duty via opening the envelopes. Reference to similar study literature is made for randomization [28, 31]. As extensively hydrolyzed milk protein formula and preterm children's formula are greatly different in color and smell, physicians and nurses can easily distinguish these two formulae. Therefore, the study has chosen singleblinding, which means that only the participants and their guardians are unaware of the milk type.

\section{Ethical aspects and informed consent}

The study has passed the review of the Clinical Study Ethics Committee of Zhongda Hospital Southeast University, and the Ethics Committee's approval number is 2014ZDSYLL115.0. Only the preterm children whose guardians give informed written consent will be included in this trial.

\section{Study time}

The study started in November 2014 and is expected to end in November 2017.

\section{Interventions}

The observation group is fed with extensively hydrolyzed milk protein (100\% whey protein) formula, while the control group is fed with preterm children's formula until discharge from the NICU. After discharge, both groups are uniformly fed with ordinary formula (formula for 0 to 6-month-old infants).

\section{Study design and outcomes \\ Outcomes}

The first endpoint variable is the rate of food intolerance in preterm children. The second endpoint variables include (1) time to achieve full enteral nutrition; (2) time of parenteral nutrition; (3) time of NICU stay; (4) meconium drainage time; (5) daily spontaneous fecal discharge conditions; (6) growth and development conditions during the NICU stay and within 3 months after discharge, including daily weight growth rate, weekly body length growth rate and weekly head circumference growth rate; (7) different plasma parameter indicators before discharge from the NICU (total protein (TP), albumin, calcium (Ca), phosphorus (P), and alkaline phosphatase (ALP)). Other endpoint variables include the incidences of neonatal necrotizing enterocolitis, cholestasis, parenteral nutritionassociated cholestasis and congenital hypothyroidism $(\mathrm{CH})$.

\section{Study design}

The study includes two stages. In stage I, the study observes the incidence of feeding intolerance, parenteral nutrition conditions, spontaneous fecal discharge conditions, growth and development conditions and the incidence of other preterm children's complications in the preterm children in the two groups during the NICU stay. In this stage, different feeding methods and parenteral nutrition are regulated according to the gestational age, birth weight and days after birth of the preterm children, and unified diagnostic criteria and treatment methods for different complications are developed. In 
stage II, the study follows up the growth and development conditions of the preterm children in the two groups on a regular basis after discharge from the NICU.

\section{Introduction to the formulae}

The two kinds of formula for feeding during the NICU stay and the formula for feeding after discharge from the NICU are all Dumex, a brand of French Danone-Nutricia for early life nutrition. In this study, the gestational age of all preterm children when discharged from the NICU is all $\geq 34$ weeks, and thus formula suitable for 0 to 6-month-old infants is uniformly chosen for them after discharge. The ingredients of such formulae are shown in Table 1.

\section{Stage I: NICU stay}

\section{Feeding time}

- Preterm children without obvious high-risk factors are fed within 24 hours after birth.

- The feeding of preterm children with birth weight $<1000 \mathrm{~g}$, obvious history of asphyxia at birth (Apgar score $\leq 5$ ), severe infection (sepsis, purulent meningitis, etc.), severe pneumonia or neonatal respiratory distress syndrome (NRDS) requiring intubation and mechanical ventilation should be postponed to 24-72 h after birth according to the situation.

- During the period when full enteral nutrition is not achieved, partial parenteral nutrition is given according to the daily amount of fluid and energy required by the children; when the children experience feeding intolerance and necrotizing enterocolitis and need to be fasting, complete parenteral nutrition is given; after the conditions are stable, the children gradually switch to enteral nutrition and are fed until discharge or transfer into DRI.

- Children in the two groups are fed with ordinary formula after discharge or transfer to DRI.

\section{Feeding methods}

- For preterm children with a gestational age of $<32$ weeks, since their sucking-swallowing action is uncoordinated and respiratory function is not maturely developed, the children are given tube feeding (nasogastric tube or orogastric tube) using the intermittent infusion feeding method. Every time before feeding, the stomach contents are drawn to learn about gastric residual volume (GRV) and nature.

- Children suspected of suffering from gastroesophageal reflux or delayed gastric emptying are fed by adopting intermittent/continuous infusion feeding method with an infusion pump.
- Preterm children with a gestational age of 32-34 weeks are given direct bottle feeding.

- Children with weak sucking ability yet normal gastric emptying are given bottle feeding first, and then the remaining milk is given by tube feeding.

- Children with nasal continuous positive airway pressure (nCPAP) or intubation and mechanical ventilation are given tube feeding;

- During tube feeding or fasting period, the children are given non-nutritive sucking (NNS).

3. Feeding milk volume

- Initial feeding milk volume: according to birth weight, the children are fed from different initial milk volume once every two hours, as shown in Table 2.

- The milk volume begins to increase in the absence of feeding intolerance in 24-h observation, and the rates for milk increasing are shown in Table 2.

4. Fluid amount control [14, 47]

Fluid amount includes the total amount of enteral nutrition, parenteral nutrition and all other intravenous and oral medications. If birth weight is $<1500 \mathrm{~g}$, the fluid amount in the first 24 hours after birth is $80-100 \mathrm{ml} /(\mathrm{kg} / \mathrm{d})$; if birth weight is $\geq 1500 \mathrm{~g}$, the fluid amount in the first 24 hours after birth is $60-100 \mathrm{ml} /(\mathrm{kg} / \mathrm{d})$; then the amount is incremented at a rate of $15-20 \mathrm{ml} /(\mathrm{kg} / \mathrm{d})$ to reach $150 \mathrm{ml} /(\mathrm{kg} / \mathrm{d})$ by the end of the first week; daily fluid amount is increased or decreased by $10-20 \mathrm{ml} / \mathrm{kg}$ on the basis of the fluid amount that day according to different clinical conditions (light therapy, incubator, ventilator, heart and lung function, urine amount, systemic edema conditions, biochemical monitoring indicators, etc.), usually no more than $180 \mathrm{ml} /(\mathrm{kg} / \mathrm{d})$.

\section{Calorie control $[14,47]$}

Calorie includes the total calories provided by enteral feeding and parenteral nutrition. The calorie on the first day is $40 \mathrm{kcal} / \mathrm{kg}$ and then incremented at a rate of $10 \mathrm{kcal} /(\mathrm{kg} / \mathrm{d})$. Parenteral nutrition is stopped when enteral nutrition reaches $80-100 \mathrm{kcal} /(\mathrm{kg} / \mathrm{d})$, and enteral nutrition $100-120 \mathrm{kcal} /(\mathrm{kg} / \mathrm{d})$ is the criterion to achieve full enteral nutrition.

\section{Parenteral nutrition (PN) $[14,47]$}

- Vessel selection: peripheral vein or central vein, central vein includes peripherally inserted central catheter (PICC) and umbilical venous catheter (PVC). 
Table 1 Table of ingredients of the three formulae

\begin{tabular}{|c|c|c|c|}
\hline Ingredients & $\begin{array}{l}\text { Preterm children's formula } \\
(/ 100 \mathrm{ml})\end{array}$ & $\begin{array}{l}\text { Extensively hydrolyzed formula } \\
(/ 100 \mathrm{ml})\end{array}$ & $\begin{array}{l}\text { Formula for } 0 \text { to 6-month-old } \\
\text { infants (/100 ml) }\end{array}$ \\
\hline Energy (kcal/KJ) & $80 / 336$ & $66 / 278$ & $67 / 282$ \\
\hline Osmolality (mOsmol/L) & 360 & 250 & - \\
\hline Fat (g) & 3.8 & 3.5 & 3.5 \\
\hline a-linolenic acid (mg) & 44 & 58 & 42 \\
\hline Linoleic acid (g) & 0.6 & 0.41 & 0.42 \\
\hline Oleic acid (g) & 1.3 & 1.2 & - \\
\hline Medium-chain triglyceride content (\%) & $30 \%$ & $40 \%$ & - \\
\hline Protein (g) & 2.6 (60 \% whey protein and $40 \%$ casein) & 1.6 (100 \% whey protein) & 1.4 \\
\hline Carbohydrates & 8.4 & 6.9 & 7.1 \\
\hline Lactose $(g)$ & 5.6 & 2.8 & - \\
\hline $\begin{array}{l}\text { Prebiotics (galactooligosaccharides, } \\
\text { polyfructose) (g) }\end{array}$ & 0.8 & 0.8 & 0.8 \\
\hline Arachidonic acid (mg) & 19 & 6.6 & 12 \\
\hline Docosahexaenoic acid (mg) & 15 & 6.6 & 12 \\
\hline Taurine (mg) & 5.5 & 5.3 & 5.4 \\
\hline L-carnitine (mg) & 1.8 & 1 & 1.5 \\
\hline Nucleotides (mg) & 3.4 & 3.2 & 3.0 \\
\hline Vitamin A $(\mu \mathrm{g})$ & 359 & 52 & 65 \\
\hline Vitamin D $(\mu \mathrm{g})$ & 3 & 1.3 & 0.95 \\
\hline Vitamin E (mg) & 3.5 & 1 & 1.2 \\
\hline Vitamin K1 ( $\mu \mathrm{g})$ & 6 & 4.7 & 5.4 \\
\hline Vitamin B1 ( $\mu \mathrm{g})$ & 139 & 50 & 58 \\
\hline Vitamin B2 ( $\mu \mathrm{g})$ & 199 & 99 & 103 \\
\hline Vitamin B6 $(\mu \mathrm{g})$ & 119 & 40 & 48 \\
\hline Vitamin B12 $(\mu \mathrm{g})$ & 0.24 & 0.18 & 0.31 \\
\hline Nicotinamide acid $(\mu \mathrm{g})$ & 2352 & 432 & 517 \\
\hline Folic acid $(\mu \mathrm{g})$ & 35 & 9 & 11 \\
\hline Pantothenic acid $(\mu \mathrm{g})$ & 876 & 327 & 354 \\
\hline Vitamin C (mg) & 17 & 9 & 9.2 \\
\hline Biotin $(\mu g)$ & 3.5 & 2.2 & 2.3 \\
\hline Choline (mg) & 17 & 10 & 16 \\
\hline Inositol (mg) & 24 & 3.2 & 3.8 \\
\hline Sodium (mg) & 70 & 20 & 20 \\
\hline Potassium (mg) & 80 & 75 & 69 \\
\hline Copper $(\mu g)$ & 80 & 40 & 48 \\
\hline Magnesium (mg) & 8 & 5.1 & 5.7 \\
\hline Iron (mg) & 1.6 & 0.53 & 0.71 \\
\hline Zinc (mg) & 1.1 & 0.5 & 0.5 \\
\hline Manganese $(\mu \mathrm{g})$ & 10 & 7.4 & 7.5 \\
\hline Calcium (mg) & 100 & 47 & 52 \\
\hline Phosphorus (mg) & 56 & 26 & 31 \\
\hline lodine $(\mu \mathrm{g})$ & 25 & 12 & 11 \\
\hline Chlorine (mg) & 85 & 41 & 48 \\
\hline Selenium $(\mu \mathrm{g})$ & 4.5 & 1.5 & 2.2 \\
\hline
\end{tabular}


Table 2 Initial feeding milk volume and increasing rate in the two groups of preterm children

\begin{tabular}{lll}
\hline Birth weight $(\mathrm{g})$ & $\begin{array}{l}\text { Initial feeding milk } \\
\text { volume }(\mathrm{ml} / \mathrm{kg})\end{array}$ & $\begin{array}{l}\text { Increasing rate } \\
(\mathrm{ml} / \mathrm{kg} / \mathrm{d})\end{array}$ \\
\hline$<1000$ & 1.0 & 12 \\
$1000-1500$ & $1.0-2.0$ & $12-24$ \\
$1501-2000$ & 2.0 & $24-36$ \\
$>2000$ & 2.0 & 36 \\
\hline
\end{tabular}

- Method: all children adopt "all in one" parenteral nutrition. The nutrient solution used for daily parenteral nutrition is uniformly prepared inside on a clean bench at the hospital's Intravenous Nutrition Preparation Center according to the doctor's instructions that day, and attention should be paid to the sequence of mixing during preparation. After preparation the solution is evenly infused via the infusion pump within 24 hours. The total amount of parenteral nutrition fluid and compounding ratio of all nutrients are calculated according to the child's total fluid amount required that day, total calorie, milk intake the day before and possible total milk intake that day.

- Children's compound amino acid (6 \%) 1.0-1.5 g/ $(\mathrm{kg} / \mathrm{d})$ is added within 24 hours after birth, which is later incremented up to $3.5-4.0 \mathrm{~g} /(\mathrm{kg} / \mathrm{d})$ at a rate of $0.5 \mathrm{~g} /(\mathrm{kg} / \mathrm{d})$; medium and long-chain fat emulsion $0.5 \mathrm{~g} /(\mathrm{kg} / \mathrm{d})$ is added within 24 hours after birth, which is later incremented up to $3.0 \mathrm{~g} /(\mathrm{kg} / \mathrm{d})$ at a rate of $0.5 \mathrm{~g} /(\mathrm{kg} / \mathrm{d})$.

- Carbohydrates $\leq 15 \mathrm{~g} /(\mathrm{kg} / \mathrm{d})$, providing $40-50 \%$ of the total energy; amino acids $\leq 3.5-4.0 \mathrm{~g} /(\mathrm{kg} /$ d), providing $15-20 \%$ of the total energy, fat emulsion $\leq 3.0 \mathrm{~g} /(\mathrm{kg} / \mathrm{d})$, providing $40-50 \%$ of the total energy.

- Sodium ions $2.0-3.0 \mathrm{mmol} / \mathrm{L}$ and potassium ions 1.0-2.0 $\mathrm{mmol} / \mathrm{L}$ are supplemented daily, but within 3 days after birth, no potassium is supplemented in principle unless the child is suffering from hypokalemia.

- A variety of water-soluble and fat-soluble vitamins $0.5-1.0 \mathrm{ml} /(\mathrm{kg} / \mathrm{d})$ are supplemented.

- If the child has cholestasis, the amount of intravenous fat emulsion is reduced.

- The concentration and rate of intravenous nutritive sugar are adjusted according to the child's blood glucose monitoring. In case of PVC or PICC, the sugar concentration is $\leq 15 \%$; when peripheral intravenous infusion is adopted, the sugar concentration is $\leq 12.5 \%$. The child's blood glucose is controlled at $3.0-7.0 \mathrm{mmol} / \mathrm{L}$.
7. Diagnostic criteria for and treatment of various complications:

1. Diagnostic criteria for and clinical treatment of feeding intolerance $[48,49]$

Children in line with any of the following six criteria can be diagnosed with feeding intolerance:

- Gastric residual liquid $>50 \%$ of the amount of previous feeding

- Vomiting $\geq 3$ times/day, or the vomitus is bile-like

- Gastric residual liquid or vomitus is bile-like or coffee grounds-like

- Abdominal distension (abdominal girth is increased by $\geq 1.5 \mathrm{~cm}$ within 24 hours, with intestinal type), and abdominal distension caused by the use of nCPAP should be ruled out

- Required fasting $>2$ meals

- Blood in the stool or fecal occult blood positive, but it is required to rule out NEC based on the general conditions, blood indicators and abdominal X-ray examination of children

\section{Clinical treatments:}

- Amount of gastric residue: for children with tube feeding, draw the residual milk in the stomach every time before feeding.

(a) If birth weight is $<1500 \mathrm{~g}$, and gastric residue is $<2 \mathrm{ml}$ or if birth weight is $\geq 1500 \mathrm{~g}$ and gastric residue is $<3 \mathrm{ml}$ or gastric residue is $<30 \%$ of the amount of previous feeding, continue feeding and closely observe.

(b)If gastric residue is $30-50 \%$ of the amount of previous feed, reduce the amount of feeding.

(c) If gastric residue is $>50 \%$ of the amount of previous feeding, fast for one meal, and continue feeding by the original feeding plan after the condition is improved.

(d)If there is bile-like or coffee grounds-like liquid in the gastric residual liquid or vomitus, stop feeding.

- Abdominal distension: measure the abdominal girth at fixed parts every time before feeding. If the abdominal girth is increased by $\geq 1.5 \mathrm{~cm}$, reduce the amount of feeding or fast for one meal, and continue feeding by the original feeding plan after the abdominal distension condition is improved.

- If daily vomiting occurs $>3$ times, do not increase the milk volume or reduce the amount of feeding.

- In the event of blood in the stool or fecal occult blood positive, stop feeding. 
2. Diagnostic and treatment reference criteria for necrotizing enterocolitis (NEC) [50] are shown in Table 3.

3. Diagnostic criteria for and clinical treatment of cholestasis:

Diagnostic criteria [51]: in line with any of the first two criteria:

- Total bilirubin (TB) $<5 \mathrm{mg} / \mathrm{dl}$ and direct bilirubin (DB) $>1.0 \mathrm{mg} / \mathrm{dl}$

- $\mathrm{TB}>5 \mathrm{mg} / \mathrm{dl}$ and $\mathrm{DB}>20 \%$ of TB

- Elevated total bile acid (TBA) levels alone cannot serve as a diagnostic criterion for cholestasis

4. Diagnosis and clinical treatment of parenteral nutrition-associated cholestasis (PNAC):

Diagnostic criteria for PNAC [52]:

- Continuous parenteral nutrition $\geq 14$ days

- Serum DB >34umol/L (2 mg/d1)

- Clinical manifestations of yellowish discoloration of skin, hepatosplenomegaly, elevated transaminase levels and (or) lighter stool color

- Exclusion of other diseases causing cholestasis (various biliary malformations causing biliary obstruction, hereditary metabolic diseases and hepatitis caused by bacterial and viral infections)

\section{Clinical treatment of PNAC:}

- Protect the liver and gallbladder: ursodesoxycholic acid $15 \mathrm{mg} /(\mathrm{kg} / \mathrm{d})$, three times daily, by mouth

- Do not lightly fast; increase enteral nutrition, reduce the proportion of parenteral nutrition, and medium and long-chain fat emulsion $\leq 1 \mathrm{~g} /(\mathrm{kg} / \mathrm{d})$

- Additionally supplement vitamin E $10 \mathrm{mg} /(\mathrm{kg} / \mathrm{d})$, twice daily, by mouth

5. Diagnostic criteria for and clinical treatment of congenital hypothyroidism [53].

Diagnostic criteria: 1 week after birth, draw blood to test serum thyroid-stimulating hormone (TSH), total triiodothyronine $\left(\mathrm{TT}_{3}\right)$, total thyroxine $\left(\mathrm{TT}_{4}\right)$, free triiodothyronine $\left(\mathrm{FT}_{3}\right)$ and free thyroxine $\left(\mathrm{FT}_{4}\right)$. If blood test shows no abnormality but there are clinically suspicious symptoms of hypothyroidism, retest the thyroid function. Suspicious symptoms of preterm children's hypothyroidism include persistent jaundice, lethargy, less crying, low and weak crying, slow heart rate, low and blunt heart sounds, poor digestion (weak sucking, feeding intolerance), recurrent hypoglycemia, etc.
- If blood TSH is $>10 \mathrm{mU} / \mathrm{L}$ and $\mathrm{FT}_{4}$ is decreased, the child will be diagnosed with congenital hypothyroidism.

- If blood TSH is $>10 \mathrm{mU} / \mathrm{L}$ and $\mathrm{FT}_{4}$ is normal, the child will be diagnosed with high TSH hyperlipidemia.

- If blood TSH is normal or decreased and $\mathrm{FT}_{4}$ is decreased, the child will be diagnosed with secondary or central hypothyroidism.

Clinical treatment:

- In line with criterion (1), levothyroxine (Euthyrox) from a starting therapeutic dose of $10-15 \mathrm{ug} /(\mathrm{kg} / \mathrm{d})$, daily, by mouth.

- In line with criterion (2), retest 1 week later. If TSH is still $>10 \mathrm{mU} / \mathrm{L}$, give Euthyrox $4-8 \mathrm{ug} / \mathrm{kg} / \mathrm{d}$, daily, by mouth.

- In line with criterion (3), retest 1 week later. If $\mathrm{FT}_{4}$ is still decreased, give Euthyrox 4- $8 \mathrm{ug} / \mathrm{kg} / \mathrm{d}$, daily, by mouth.

- If TSH always maintains at 6-10 mU/L, without treatment, regularly follow up thyroid function.

- If $\mathrm{FT}_{4}$ and TSH are normal, children with decreased $\mathrm{TT}_{3}$ or $\mathrm{TT}_{4}$ are given no treatment.

- For children with abnormal test results, draw blood for retest in 1-2 weeks. Adjust the therapeutic dose based on the concentrations of blood TSH and $\mathrm{FT}_{4}$ and the children's weight.

6. Diagnostic criteria for and clinical treatment of hypocalcemia [54]

Diagnostic criteria:

Total serum calcium is less than $1.75 \mathrm{mmol} / \mathrm{L}(7.0 \mathrm{mg} / \mathrm{dl})$ or free calcium is less than $0.9 \mathrm{mmom} / \mathrm{L}(3.5 \mathrm{mg} / \mathrm{dl})$.

\section{Clinical treatment:}

- For children with clinical seizures or heart rhythm disorders, which cannot be explained by other diseases, give them slow intravenous injection of $10 \%$ calcium gluconate $2 \mathrm{ml} / \mathrm{kg}$, and use $5 \%$ glucose injection after dilution by onefold. Then according to the retest result, decide whether to continue intravenous injection or switch to oral medication.

- For children with stable conditions, give them tube feeding or oral $10 \%$ calcium gluconate.

\section{Stage II: follow-up period after discharge from the NICU}

1. Develop a follow-up observation table for preterm children $<34$ weeks, and require the children's health 
Table 3 Modified Bell staging criteria for neonatal necrotising enterocolitis

\begin{tabular}{|c|c|c|c|c|}
\hline Staging & Systemic symptoms & Gastrointestinal symptoms & Radiological signs & Treatment \\
\hline IA Suspected NEC & $\begin{array}{l}\text { Temperature instability, apnoea, } \\
\text { bradycardia, lethargy }\end{array}$ & $\begin{array}{l}\text { Gastric retention, mild abdominal distension, } \\
\text { fecal occult blood positive }\end{array}$ & $\begin{array}{l}\text { Normal or intestinal dilation, } \\
\text { mild ileus }\end{array}$ & $\begin{array}{l}\text { Absolute fasting, gastric decompression, } \\
\text { antibiotic therapy for } 3 \text { days, waiting for } \\
\text { pathogen culture results }\end{array}$ \\
\hline IB Suspected NEC & Same as IA & Bright-red blood from rectum & Same as IA & Same as IA \\
\hline IIA proven NEC (mildly ill) & Same as IA & $\begin{array}{l}\text { Same as IA or IB, plus absent bowel sounds, } \\
\text { and (or) abdominal tenderness, }\end{array}$ & $\begin{array}{l}\text { Intestinal dilation, ileus, } \\
\text { pneumatosis intestinalis }\end{array}$ & $\begin{array}{l}\text { Same as IA, absolute fasting. If } 24-48 \mathrm{~h} \\
\text { culture shows no abnormality, use } \\
\text { antibiotics for } 7-10 \text { days }\end{array}$ \\
\hline IIB proven NEC (moderately ill) & $\begin{array}{l}\text { Same as IIA, plus mild metabolic } \\
\text { acidosis and mild thrombocytopenia }\end{array}$ & $\begin{array}{l}\text { Same as IIA,plus absent bowel sounds, definite } \\
\text { abdominal tenderness, and (or) abdominal } \\
\text { cellulitis or right lower quadrant mass }\end{array}$ & $\begin{array}{l}\text { Same as IIA, plus portal vein } \\
\text { gas, and (or) ascites }\end{array}$ & $\begin{array}{l}\text { Same as IIA, absolute fasting. Supplement } \\
\text { blood volume, treat acidosis, and use } \\
\text { antibiotics for } 14 \text { days }\end{array}$ \\
\hline $\begin{array}{l}\text { IIIA Advanced NEC } \\
\text { (severely ill, bower intact) }\end{array}$ & $\begin{array}{l}\text { Same as IIB, plus hypotension, } \\
\text { bradycardia, severe apnea, mixed } \\
\text { acidosis, DIC, neutropenia, anuria }\end{array}$ & $\begin{array}{l}\text { Same as IIB, plus signs of generalized peritonitis, } \\
\text { abdominal distension or marked tenderness, } \\
\text { and redness and swelling of abdominal wall }\end{array}$ & Same as $\| B$, ascites & $\begin{array}{l}\text { Transfer to the Surgical Department } \\
\text { of Children's Hospital for observation }\end{array}$ \\
\hline $\begin{array}{l}\text { IIIB Advanced NEC } \\
\text { (severely ill, bowel perforated) }\end{array}$ & $\begin{array}{l}\text { Same as IIIA, plus suddenly } \\
\text { aggravation of conditions }\end{array}$ & $\begin{array}{l}\text { Same as IIIA, plus sudden aggravation } \\
\text { of abdominal distension }\end{array}$ & Same as IIB, pneumoperitoneum & $\begin{array}{l}\text { Transfer to the Surgical Department } \\
\text { of Children's Hospital for surgery }\end{array}$ \\
\hline
\end{tabular}

NEC necrotising enterocolitis, DIC disseminated intravascular coagulation 
care medical staff to record the data of follow-up every time in detail.

2. Require the preterm children to revisit the hospital's Child Health Clinic for referral 2 weeks, 4 weeks and 3 months after discharge, and follow up once every 2-4 weeks according to the preterm children's conditions 4 weeks later.

3. Call the children's parents 1-2 day before every referral and require them to bring the children to our hospital for referral on time, and ask them to bring all medical data.

4. Contents of referral at the Child Health Clinic include measurement of physical growth and development, assessment of neuropsychological development, nutritional assessment and feeding guidance. According to different conditions of the preterm children during hospital stay, choose whether to conduct blood, liver function, thyroid function, head B-mode ultrasound or cranial magnetic resonance imaging (MRI), retinopathy (ROP) screening, hearing screening and other tests.

5. Explain the current follow-up results in detail to the parents, and appoint the time and contents of next follow-up.

6. Call the parents again on the night or the next day of follow-up every time to inquire about follow-up conditions in detail, and again record all follow-up results.

7. Follow-up period: at least 3 months.

\section{Data collection and management}

Including the collection of clinical data of preterm children during the NICU stay and follow-up data after discharge from the NICU.

\section{Collection of clinical data during the NICU stay}

1. Collection of general data of the objects of study:

(a) Sex, gestational age, birth weight, birth head circumference, birth body length, mode of delivery, 5-minute Apgar score, etc., of preterm children

(b) Mother's pregnancy complications and comorbidities: premature rupture of membrane $>24$ hours, placental abruption, chorioamnionitis, pregnancy-induced hypertension syndrome, preeclampsia, gestational diabetes, hyperthyroidism, hypothyroidism, systemic lupus erythematosus, kidney disease, cholestasis, acute liver failure, syphilis infection, etc.

(c) Special treatment: nasal continuous positive airway pressure (nCPAP), intubation and mechanical ventilation $(\mathrm{MV})$, use of pulmonary surfactant (PS), thoracentesis, bone marrow biopsy, thoracic drainage, peritoneal dialysis, etc.
2. Collection of case data during the NICU stay:

Incidence and outcome of feeding intolerance in preterm children, neonatal necrotizing enterocolitis, cholestasis, parenteral nutrition-associated cholestasis and congenital hypothyroidism

3. Collection of enteral and parenteral nutrition and defecation conditions during the NICU stay:

(a) Milk opening time (h), total amount of daily milk $(\mathrm{ml})$ and calories $(\mathrm{kcal})$, total amount of daily parenteral nutrition $(\mathrm{ml})$ and calories (kcal), total volume of daily fluids (ml) and total calories (kcal)

(b) The number of daily bowel movements, times of daily enema, trait and color of stool every time, meconium drainage time (h)

(c) Gastric residual volume ( $\mathrm{ml}$ ) and nature, times and nature of vomiting, and abdominal distension

(d) Time to achieve full enteral nutrition (d), and total time of parenteral nutrition

4. Collection of physical growth and development indicators during the NICU stay:

(a) Weight: weight will be measured at admission, once every day during hospital stay and before discharge with a baby electronic scale, and the data will be accurate to $10 \mathrm{~g}$.

(b)Body length: body length will be measured at admission, once every week during hospital stay and before discharge, and the data will be accurate to $0.1 \mathrm{~cm}$.

(c) Head circumference: head circumference will be measured at admission, once every week during hospital stay and before discharge, and the data will be accurate to $0.1 \mathrm{~cm}$.

5. Collection of laboratory indicators during the NICU stay:

(a) Daily monitoring of peripheral blood glucose and transcutaneous bilirubin

(b)Weekly detection of blood, liver and kidney function (total protein, albumin, total bilirubin, direct bilirubin, alkaline phosphatase, bile acids, alanine aminotransferase, aspartate aminotransferase, $\gamma$-glutamyl transferase, urea nitrogen, creatinine) and electrolytes (mainly calcium and phosphorus)

(c) Test of serum thyroid function 1-2 weeks after admission, including $\mathrm{TSH}, \mathrm{TT}_{3}, \mathrm{TT}_{4}, \mathrm{FT}_{3}$ and $\mathrm{FT}_{4}$

\section{Collection of follow-up data after discharge from the NICU}

1. Weight: weight will be measured once 2 weeks, 4 weeks and 3 months after discharge, respectively, and the data will be accurate to $10 \mathrm{~g}$. 
2. Body length: body length will be measured once 2 weeks, 4 weeks and 3 months after discharge, respectively, and the data will be accurate to $0.1 \mathrm{~cm}$.

3. Head circumference: head circumference will be measured once 2 weeks, 4 weeks and 3 months after discharge, respectively, and the data will be accurate to $0.1 \mathrm{~cm}$.

\section{Sample size justification}

We calculate the sample size based on the chi-square test comparison of the food intolerance rate during NICU between groups. Our previous pilot study shows that the rate of food intolerance during NICU for control patients is about $85 \%$. We expect that the intervention group will have a reduced intolerance rate to be $75 \%$. With these assumptions, we will need 148 infants in each group to finish the NICU part of the study to reach $80 \%$ power and $5 \%$ Type I error rate. Assuming that the dropout rate to be $20 \%$, we will need to enroll 185 infants in each group.

\section{Statistical analysis \\ Preliminary analysis}

Patients' characteristics will be summarized using mean \pm $\mathrm{SD}$ for continuous variables and frequency (percentage) for categorical variables by groups. Continuous variables will be transformed if there is a normal assumption violation.

\section{Primary outcome}

The rates of food intolerance during NICU will be summarized and compared using the chi-square test. A $p$ value $<0.05$ indicates a significant difference in rates between the two groups. We will also fit the logistic regression model with food intolerance status as the outcome variable, and group as the main predictor adjusting for covariates. In the case that the number of intolerance events is large enough, we will consider using a Poisson model to model the number of intolerances.

\section{Secondary outcome}

The time to reach enteral nutrition (parenteral nutrition), length of hospital stay, meconium drainage time during the NICU stay will be summarized and compared using Kaplan-Meier estimators and logrank tests. Cox models will also be fitted for time-to-event data adjusting for baseline covariates. The number of times of selfdefecating per day will be compared using the Poisson model adjusting for baseline covariates. The rates of comorbidity will be compared using Poisson models. The plasma total protein, albumin level, calcium, alkaline phosphatase levels before discharge from the NICU will be compared using $t$ tests. Growth rates measure by weight, body length, and head circumference during the
NICU and within 3 months of discharge will be analyzed using repeated measurement analysis of covariance models. All analysis will be conducted using SAS 9.4 (SAS Institute, Cary, NC, USA).

\section{Discussion}

Extensively hydrolyzed milk protein formula can accelerate gastric emptying and gastrointestinal transit time, and promote gastrointestinal hormone secretion, and these mechanisms are conducive for the gastrointestinal tolerability of preterm children, thereby lowering the incidence of gastroesophageal reflux and feeding intolerance in preterm children, achieving full enteral nutrition as soon as possible and reducing the time of parenteral nutrition. In China, more and more medical organizations have started using extensively hydrolyzed milk protein formula to feed preterm children, but so far there is no clear conclusion on whether low-energy low-protein extensively hydrolyzed formula can meet the high nutritional needs of preterm children in the feeding period, and there is a lack of relevant studies and conclusions on whether feeding with extensively hydrolyzed milk protein formula in the early stage of life will affect the subsequent growth and development of preterm children. As the conflict between the high nutritional needs and low gastrointestinal tolerability of preterm children with a gestational age of less than 34 weeks is an unavoidable issue, we have designed this study protocol, aiming to increase a new and truly safe and effective enteral nutritional prescription. Our study observes the effect of extensively hydrolyzed milk formula on the feeding intolerance, enteral and parenteral nutrition, spontaneous fecal discharge and other complications in preterm children with a gestational age of less than 34 weeks during the NICU stay; it also is the first controlled clinical study with long-term observation of the growth and development of preterm children fed with such formula in the early stage of life. Our study time includes NICU stay and 3-month follow-up after discharge of preterm children. The results of this study will confirm that feeding preterm children with such formula during the NICU stay is safe and effective, and does not affect the normal growth and development of preterm children in the early stage of their lives.

\section{Trial status}

We started the enrollment in November 2014 and the trial is expected to end in November 2017.

\section{Abbreviations}

AAP: American Academy of Pediatrics; ALB: serum albumin; ALP: alkaline phosphatase; Ca: calcium; CH: congenital hypothyroidism; CMPA: cow's milk protein allergy; CT: computed tomography; DB: direct bilirubin; DRI: direct rooming-in; EF: enteral feeding; EHF: extensively hydrolyzed formula; ESPGHAN: European Society for Pediatric Gastroenterology, Hepatology, and Nutrition; EUGR: extrauterine growth restriction; Fl: feeding intolerance; 
$\mathrm{FT}_{3}$ : free triiodothyronine; $\mathrm{FT}_{4}$ : free thyroxine; GAS: gastrin;

GER: gastroesophageal reflux; GRV: gastric residual volume; LCT: long-chain fatty acids; MCF: medium-chain triglycerides fat; MMC: migrating motor complex; MOT: motilin; MRI: magnetic resonance imaging; MV: mechanical ventilation; nCPAP: nasal continuous positive airway pressure; NEC: necrotising enterocolitis; NICU: Neonatal Intensive Care Unit; NNS: nonnutritive sucking; NRDS: newborn respiratory distress syndrome; P: phosphorus; P/E: protein-to-energy ratio; PICC: peripherally inserted central catheter; PN: parenteral nutrition; PNAC: parenteral nutrition-associated cholestasis; PS: pulmonary surfactant; PVC: percutaneous umbilical vein catheter; ROP: retinopathy; TB: total bilirubin; TBA: total bile acid; TP: total protein $\mathrm{TSH}$ : thyroid-stimulating hormone; $\Pi_{3}$ : total triiodothyronine; $\Pi_{4}$ : total thyroxine; WHO: World Health Organization.

\section{Competing interests}

The authors declare that there are no conflicts of interests regarding this study.

\section{Authors' contributions}

$L P Y, L J Q$ and LXQ designed the study and wrote the protocol. $\mathrm{HZ}$ and JNH revised the manuscript. LXQ is the leader and supervisor of the project. LPY and $L Q$ are the main persons responsible for the whole study. LPY, HZ and $\mathrm{HL}$ will do the data collection and statistical analysis. LPY, LJQ, YC and JNH are the physicians who will conduct this study in the hospital. All authors read and approved the final version of the manuscript.

\section{Acknowledgements}

We would like to thank Prof. Meng Tang from department of virology, Southeast University, China, for his help in the design of this trial. We also appreciate the constructive advice from Prof. Hongli Tang from Zhongda Hospital for the ethical review of this study. Li-Xing Qiao is funded by the National Natural Sciences Foundation of China under the number 81370739 Li-Juan Qian is funded by the Natural Sciences Foundation of Jiangsu Province, China, with number BK20151420. There is no specific funding support for the present study.

\section{Received: 22 April 2015 Accepted: 23 October 2015}

\section{Published online: 04 November 2015}

\section{References}

1. World Health Organization. Recommended definitions, terminology and format for statistical tables related to the perinatal period and use of a new certificate for cause of perinatal deaths. Modifications recommended by FIGO as amended October 14, 1976. Acta Obstet Gynecol Scand. 1977:56:247-53.

2. Raju TN, Higgins RD, Stark AR, Leveno KJ. Optimizing care and outcome for late-preterm (near-term) infants: a summary of the workshop sponsored by the National Institute of Child Health and Human Development. Pediatrics. 2006;118:1207-14.

3. Blencowe $H$, Cousens $S$, Chou D, Oestergaard M, Say L, Moller A, et al. Born too soon: the global epidemiology of 15 million preterm births. Reprod Health. 2013;10 Suppl 1:S2

4. Howson C, Kinney M, Lawn J. Born too soon: the global action report on preterm birth. Geneva: World Health Organization; 2012.

5. Blencowe H, Cousens S, Oestergaard MZ, Chou D, Moller A, Narwal R, et al. National, regional, and worldwide estimates of preterm birth rates in the year 2010 with time trends since 1990 for selected countries: a systematic analysis and implications. Lancet. 2012;379:2162-72.

6. Liu L, Johnson HL, Cousens S, Perin J, Scott S, Lawn JE, et al. Global, regional, and national causes of child mortality: an updated systematic analysis for 2010 with time trends since 2000. Lancet. 2012;379:2151-61.

7. Rudan I, Chan KY, Zhang JS, Theodoratou E, Feng XL, Salomon JA, et al. Causes of deaths in children younger than 5 years in China in 2008. Lancet. 2010;375:1083-9.

8. Neu J. Gastrointestinal maturation and implications for infant feeding. Early Hum Dev. 2007;83:767-75.

9. Lau C, Smith E, Schanler R. Coordination of suck-swallow and swallow respiration in preterm infants. Acta Paediatr. 2003:92:721-7.

10. Patole S. Developmental physiology of the gastrointestinal tract and feed intolerance in preterm neonates. In: Nutrition for the preterm neonate. Dordrecht: Springer; 2013. p. 3-23.
11. Riskin A, Agostoni C, Shamir R. Physiology of the gastrointestinal. In: Buonocore G, Bracci R, Weindling M, editors. Neonatology: a practical approach to neonatal diseases. 1st ed. Milan: Springer; 2012. p. 263-80.

12. Franz AR, Pohlandt F, Bode $H$, Mihatsch WA, Sander S, Kron M, et al. Intrauterine, early neonatal, and postdischarge growth and neurodevelopmental outcome at 5.4 years in extremely preterm infants after intensive neonatal nutritional support. Pediatrics. 2009;123:e101-9.

13. Greer FR, Olsen IE. How fast should the preterm infant grow? Current Pediatrics Reports. 2013;1:240-6.

14. Hay Jr WW. Aggressive nutrition of the preterm infant. Current Pediatrics Reports. 2013;1:229-39.

15. Montenegro BL, Martin CR. Impact of feeding and medical practices on the development of necrotizing enterocolitis. Current Pediatrics Reports. 2014;2:255-63.

16. Meier PP, Engstrom JL, Patel AL, Jegier BJ, Bruns NE. Improving the use of human milk during and after the NICU stay. Clin Perinatol. 2010;37:217-45.

17. Simmer K, Hartmann B. The knowns and unknowns of human milk banking. Early Hum Dev. 2009;85:701-4.

18. Unger S, Gibbins S, Zupancic J, Deborah L. DoMINO: donor milk for improved neurodevelopmental outcomes. BMC Pediatr. 2014;14:123.

19. Chang F, Cheng S, Wu T, Fang L. Characteristics of the first human milk bank in Taiwan. Pediatr Neonatol. 2013;54:28-33.

20. Keim SA, McNamara KA, Jayadeva CM, Braun AC, Dillon CE, Geraghty SR Breast milk sharing via the internet: The practice and health and safety considerations. Matern Child Health J. 2014;18:1471-9.

21. Tudehope D, Vento M, Bhutta Z, Pachi P. Nutritional requirements and feeding recommendations for small for gestational age infants. J Pediatr. 2013;162:S81-9.

22. Lapillonne A, Griffin IJ. Feeding preterm infants today for later metabolic and cardiovascular outcomes. J Pediatr. 2013;162:S7-16.

23. Meinzen-Derr J, Poindexter B, Wrage L, Morrow A, Stoll B, Donovan E. Role of human milk in extremely low birth weight infants' risk of necrotizing enterocolitis or death. J Perinatol. 2009;29:57-62.

24. Lin PW, Stoll BJ. Necrotising enterocolitis. Lancet. 2006;368:1271-83.

25. Boyd CA, Quigley MA, Brocklehurst P. Donor breast milk versus infant formula for preterm infants: systematic review and meta-analysis. Arch Dis Child Fetal Neonatal Ed. 2007:92:F169-75.

26. Greer FR, Sicherer SH, Burks AW. American Academy of Pediatrics Committee on Nutrition, American Academy of Pediatrics Section on Allergy and Immunology. Effects of early nutritional interventions on the development of atopic disease in infants and children: the role of maternal dietary restriction, breastfeeding, timing of introduction of complementary foods, and hydrolyzed formulas. Pediatrics. 2008;121:183-91.

27. Koletzko S, Niggemann B, Arato A, Dias JA, Heuschkel R, Husby S, et al. Diagnostic approach and management of cow's-milk protein allergy in infants and children: ESPGHAN GI Committee practical guidelines. J Pediatr Gastroenterol Nutr. 2012;55:221-9.

28. Szajewska H, Mrukowicz J, Stoiska B, Prochowska A. Extensively and partially hydrolysed preterm formulas in the prevention of allergic diseases in preterm infants: a randomized, double-blind trial. Acta Paediatr. 2004;93:1159-65.

29. Kwinta P, Sawiec P, Klimek M, Lis G, Cichocka-Jarosz E, Pietrzyk JJ. Correlation between early neonatal diet and atopic symptoms up to 5-7 years of age in very low birth weight infants: follow-up of randomized, double-blind study. Pediatr Allergy Immunol. 2009;20:458-66

30. Frati F, Garzi A, Messina M, Carfagna L, Zagordo L, Belcastro M, et al. An extensively hydrolysed cow's milk formula improves clinical symptoms of gastroesophageal reflux and reduces the gastric emptying time in infants. Allergol Immunopathol. 2002;30:36-41.

31. Staelens S, Van Den Driessche M, Barclay D, Carrié-Faessler A, Haschke F, Verbeke $\mathrm{K}$, et al. Gastric emptying in healthy newborns fed an intact protein formula, a partially and an extensively hydrolysed formula. Clin Nutr. 2008;27:264-8.

32. Mihatsch W, Högel J, Pohlandt F. Hydrolysed protein accelerates the gastrointestinal transport of formula in preterm infants. Acta Paediatr. 2001;90:196-8.

33. Corvaglia L, Mariani E, Aceti A, Capretti M, Ancora G, Faldella G. Combined oesophageal impedance-pH monitoring in preterm newborn: comparison of two options for layout analysis. Neurogastroenterol Motil. 2009;21:1027-e81.

34. Riezzo G, Indrio F, Montagna O, Tripaldi C, Laforgia N, Chiloiro M, et al. Gastric electrical activity and gastric emptying in preterm newborns fed standard and hydrolysate formulas. J Pediatr Gastroenterol Nutr. 2001;33:290-5. 
35. Mihatsch WA, Franz AR, Kuhnt B, Hogel J, Pohlandt F. Hydrolysis of casein accelerates gastrointestinal transit via reduction of opioid receptor agonists released from casein in rats. Biol Neonate. 2005;87:160-3.

36. Sun FJ, Huang RZ, Xu J, Liu GS. Relationship between plasma motilin level and feeding intolerance in preterm infants. Zhongguo Dang Dai Er Ke Za Zhi. 2013;15:249-53.

37. Corvaglia L, Mariani E, Aceti A, Galletti S, Faldella G. Extensively hydrolyzed protein formula reduces acid gastro-esophageal reflux in symptomatic preterm infants. Early Hum Dev. 2013;89:453-5.

38. Mihatsch WA, Franz AR, Högel J, Pohlandt F. Hydrolyzed protein accelerates feeding advancement in very low birth weight infants. Pediatrics. 2002;110:1199-203.

39. Agostoni C, Buonocore G, Carnielli VP, De Curtis M, Darmaun D, Decsi T, et al. Enteral nutrient supply for preterm infants: commentary from the European Society of Paediatric Gastroenterology, Hepatology and Nutrition Committee on Nutrition. J Pediatr Gastroenterol Nutr. 2010;50:85-91.

40. Mihatsch WA, Pohlandt F. Protein hydrolysate formula maintains homeostasis of plasma amino acids in preterm infants. J Pediatr Gastroenterol Nutr. 1999;29:406-10.

41. Maggio L, Zuppa A, Sawatzki G, Valsasina R, Schubert W, Tortorolo G. Higher urinary excretion of essential amino acids in preterm infants fed protein hydrolysates. Acta Paediatr. 2005;94:75-84.

42. Picaud J, Rigo J, Normand S, Lapillonne A, Reygrobellet B, Claris O, et al. Nutritional efficacy of preterm formula with a partially hydrolyzed protein source: a randomized pilot study. J Pediatr Gastroenterol Nutr. 2001;32:555-61.

43. Szajewska H, Albrecht P, Stoinska B, Prochowska A, Gawecka A, LaskowskaKlita T. Extensive and partial protein hydrolysate preterm formulas: the effect on growth rate, protein metabolism indices, and plasma amino acid concentrations. J Pediatr Gastroenterol Nutr. 2001;32:303-9.

44. Yu MX, Zhuang SQ, Wang DH, Zhou XY, Liu XH, Shi LP, et al. Effects of extensively hydrolyzed protein formula on feeding and growth in preterm infants: a multicenter controlled clinical study. Zhongguo Dang Dai Er Ke Za Zhi. 2014;16:684-90.

45. Tolia V, Lin C, Kuhns LR. Gastric emptying using three different formulas in infants with gastroesophageal reflux. J Pediatr Gastroenterol Nutr. 1992;15:297-301.

46. Siegel M, Lebenthal E, Krantz B. Effect of caloric density on gastric emptying in premature infants. J Pediatr. 1984;104:118-22.

47. Gargasz A. Neonatal and pediatric parenteral nutrition. AACN Adv Crit Care 2012;23:451-64. quiz 465-6.

48. Surmeli-Onay O, Korkmaz A, Yigit S, Yurdakok M. Feeding intolerance in preterm infants fed with powdered or liquid formula: a randomized controlled, double-blind, pilot study. Eur J Pediatr. 2013;172:529-36.

49. Fanaro S. Feeding intolerance in the preterm infant. Early Hum Dev. 2013;89:513-20.

50. Walsh MC, Kliegman RM. Necrotizing enterocolitis: treatment based on staging criteria. Pediatr Clin North Am. 1986;33:179-201.

51. Benchimol El, Walsh CM, Ling SC. Early diagnosis of neonatal cholestatic jaundice: Test at 2 weeks. Can Fam Physician. 2009;55:1184-92. 12/01.

52. Klein CJ, Ravenis M, Kusenda C, Scavo L. Parenteral nutrition-associated conjugated hyperbilirubinemia in hospitalized infants. J Am Diet Assoc. 2010;110:1684-95.

53. Burgard P, Rupp K, Lindner M, Haege G, Rigter T, Weinreich SS, et al. Newborn screening programmes in Europe; arguments and efforts regarding harmonization. Part 2 . From screening laboratory results to treatment, follow-up and quality assurance. J Inherit Metab Dis. 2012;35:613-25.

54. Jain A, Agarwal R, Sankar MJ, Deorari AK, Paul VK. Hypocalcemia in the newborn. Indian J Pediatrics. 2008:75:165-9.

\section{Submit your next manuscript to BioMed Central and take full advantage of:}

- Convenient online submission

- Thorough peer review

- No space constraints or color figure charges

- Immediate publication on acceptance

- Inclusion in PubMed, CAS, Scopus and Google Scholar

- Research which is freely available for redistribution

Submit your manuscript at www.biomedcentral.com/submit 